\title{
EL SIMULACRO DE LA DESIDENTIDAD: LAS FIGURAS AUTORIALES EN EL ESPACIO AUTOFICCIONAL DE AIRA Y VILA-MATAS
}

\author{
PABLo DeCock \\ Radboud Universiteit Nijmegen
}

\begin{abstract}
"De adolescente, leyendo a Borges" me dijo Aira, "vi dónde estaba la esencia de la literatura. Eso fue definitivo, pero después descubrí, también, que la literatura no tiene una esencia, sino muchas históricas y contingentes. Así que fue fácil escapar de la órbita borgiana, tan fácil como volver, o como no haber escapado nunca". (Vila-Matas 2002: 77)
\end{abstract}

\section{INTRODUCCIÓN}

En las últimas décadas se ha producido no solo una rehabilitación del autor en el ámbito de la teoría y la práctica narrativa sino también una vuelta llamativa del sujeto al primer plano de la escena sociocultural y mediática. Curiosamente, este auge de lo autobiográfico -o sus variantes autoficcionales- y de la expansión paralela de la individualidad en nuestra sociedad contemporánea nos conduce también a interrogarnos sobre el estatuto de ese yo enunciador y a reinterpretar, por tanto, la compleja noción de autor.

El doble estatuto paradójico del autor que es, a la vez, el origen del texto y su producto -"un origen que solo se define a posteriori" (Premat 2005: 314)1- da pie a una serie de enfoques diversos (genético, hermenéutico, biográfico, etc.) que difieren según la concepción del autor adoptada y dependen de la disciplina concernida (la narratología, el análisis del discurso, la sociología, el psicoanálisis, la filosofía, etc.). Nuestro estudio va imantado por la idea de que el autor se construye en el texto. Este proceso, que la crítica ha denominado "autofiguración", encierra un componente social y un componente imaginario. Según Premat, esta "figura de sí [...] es perfectamente ambivalente y condicionada en dos

\footnotetext{
${ }^{1}$ Nos interesa destacar la observación sugerente de Premat en cuanto a la posición del autor en el triángulo edípico: "...es el padre, ya que le da su nombre y fija sus reglas; es la madre, ya que la engendra, desde sus entrañas; es el hijo, ya que su existencia en tanto que autor está determinada por la existencia previa de la obra" (Premat 2005: 315).
} 
sentidos: condicionada desde fuera, por el campo cultural en el que se incluye, condicionada desde dentro, por las resonancias con el yo ideal y con las ficciones de la escritura" (2005: 315).

Si bien esta figura de autor, que Couturier define como "I'auteur reconstruit comme principal sujet énonciatif du texte dans l'acte même de lecture" (1995: 22), es un punto de referencia importante, no toma en cuenta suficientemente las aportaciones del análisis del discurso y no corresponde, por ende, con las exigencias de nuestro análisis que sobrepasan el terreno estricto del texto literario en su concepción inmanente. En este sentido, se revela imprescindible recurrir a la triple articulación de Maingueneau (2004: 107), que distingue en la noción de autor tres niveles relacionados: el de la "personne" biográfica, el del "écrivain" o escritor -actor en el campo literario- y, finalmente, el del "inscripteur", o sea, la instancia enunciativa del texto. Jérôme Meizoz, quien volverá a cruzar las páginas de nuestro estudio, lo sintetiza de la manera siguiente:

Au regard des dimensions multiples de la notion mises en évidence durant ces dernières décennies, parler d'auteur réfère tantôt à une personne dont on peut reconstituer la trajectoire; tantôt à une instance d'énonciation que le texte construit et propose au lecteur; tantôt à une autorité philologique dans le champ littéraire, donc une valeur, un principe de classement, une composante du canon littéraire nominalement constituée. (Meizoz 2007: 42-43)

El análisis que sigue se propone privilegiar tanto el "enunciador" -por su papel central en la semiología del texto- como el "escritor" -por su papel axiológico con respecto a la tradición y el campo literario-y se servirá solo excepcionalmente de la "persona" porque no representa una categoría de análisis válida ni fiable en textos autoficcionales que se definen por su ruptura con cualquier tipo de contrato verídico o auténtico.

Ciertamente, una serie de los textos que se inscriben en el campo autoficcional contemporáneo se distingue por la recreación -salpicada de una fuerte dosis de auto-ironía- de una figura de autor desacralizada o banalizada que parece jugar con el aura benjaminiana del autor. En este sentido, parece que hay una tendencia más abarcadora de homogeneización del yo público que afecta al concepto de autoría. Esta evolución hace que el personaje escritor se refleje en ocasiones en "la imagen de un creador improductivo y parásito, un misántropo de frágil personalidad y de autocaracterización grotesca y denigratoria, cuando no se conforma con la mediocridad del oficinista o burócrata que gestiona con ombliguismo autista su carrera literaria" (Alberca 2007: 24). Escritores como el argentino César Aira (1949) y el catalán Enrique Vila-Matas (1948) son dos de los más destacados exponentes hispanos de esta modalidad autoficcional.

En primer lugar, se analizará en este trabajo cómo se plasma concretamente esta modalidad autoficcional en la obra de los dos autores tratados y en segundo lugar se mostrará que también es oportuno relacionar dicho fenómeno con el concepto -poco aplicado hasta ahora en el ámbito hispánico- de postura de Meizoz (2007), que él define como "la manière singulière d'occuper une 'position' dans le champ littéraire" (2007: 18). Como ya se ha adelantado, si bien el 
"retrato" autoficcional del yo en el texto literario, inevitablemente fragmentario y difuso, apuesta al equívoco, hace falta analizar -si no queremos pecar de cierto reduccionismo crítico- la manifestación de esta figura dispersa en sus diferentes planos de aparición (obra narrativa, ensayos, entrevistas, política de edición, etc.). La comparación entre las preguntas que suscitan estos planos del espacio autoficcional airiano (Decock 2014) acabará por dibujar una determinada figura de autor "representativa" que será contrastada con la(s) figura(s) respectiva(s) de Vila-Matas en la última parte de nuestro trabajo. Se mostrará principalmente a partir de la novela breve Cómo me reí (2005) de Aira y El mal de Montano (2002) de Vila-Matas, donde, a pesar de una semantización sui generis de la figura de autor, ambos escritores ponen en escena una serie de yoes autoficcionales que son articulados por una dialéctica de revelación y ocultamiento y que trastornan el horizonte hermenéutico del lector. Otro argumento importante que justifica el enfoque comparativo de nuestro trabajo es que se trata de dos autores que también mantienen una relación ingeniosa con la crítica y el mercado literario. Su prestigio literario actual se debe en mayor o menor medida a la forma productiva con la que han logrado imponer su propio canon. Tanto Aira como VilaMatas han sabido construir un espacio de lectura innovador a partir del cual se invita a interpretar su propia narrativa.

\section{AutOFicCIÓN FANTÁStica/BIOgRÁfiCA}

Si la autoficción no debe ser considerada como un género autónomo en una época en la que la hibridez genérica ya es un hecho asumido por la crítica, corre al mismo tiempo el riesgo de no ser reconocida como tal, ya no porque no quepa en las casillas limitadas por Lejeune $-y$, entonces, una simple excepción a la regla- sino porque todo relato es, en cierto sentido, una (auto)ficción ${ }^{2}$. Sin embargo, la autoficción no deja de ser una categoría sumamente útil para analizar una práctica literaria y estética bien difundida y muy comentada estos últimos años en el mundo académico. Cabe precisar ahora esta zona acotada por Alberca (2007) -"las novelas del yo"- para articular mejor las novelas de nuestro corpus. Por ello, recurrimos a la tipología de Colonna, discípulo de Genette, que amplió la definición de Doubrovsky - de postura realista y más representativa de la novela autobiográfica ${ }^{3}$ - en su tesis doctoral ${ }^{4}$. Colonna maneja una concepción

\footnotetext{
2 Premat también señala desde una óptica psicoanalítica que todo relato es la "puesta en escena fantasmática de peripecias pulsionales y biográficas del sujeto que escribe. Asumirse en tanto que protagonista de la ficción, como sucede en lo que la crítica literaria denomina autoficción, es llevar a sus últimas consecuencias un funcionamiento inherente al relato literario" (2005: 314).

3 En la teoría de Doubrovsky, la autoficción -según Colonna- "se confond entièrement avec le roman autobiographique nominal, une variété de la province du roman autobiographique, qui ne constitue elle-même qu'un des îlots de la fabulation de soi, et tend à masquer la luxuriance de l'archipel" (2004: 196).

${ }^{4}$ Cuando citamos de la obra de Colonna, nos referimos, en realidad, al ensayo publicado en el 2004, que constituye una reelaboración profunda de la tesis doctoral que presentó en 1989. Véanse los estudios de Alberca (2007) y Jeannelle (2007) para un comentario acerca de las diferencias entre las dos versiones de Colonna.
} 
más imaginaria o fantástica de la autoficción que designa el conjunto de procedimientos de la ficcionalización del $\mathrm{yo}^{5}$. Este es un punto crucial: ya no se trata del aspecto referencial, de la autenticidad de los hechos, sino de una valorización del imaginario literario (Jeannelle 2007: 21).

En particular, nos interesa destacar en la tipología propuesta por Colonna ${ }^{6}$ la "autoficción fantástica", que es no solamente la variante más próxima a su definición general sino también la más adecuada para enfocar la obra de Aira. Él la define de la manera siguiente: "L'écrivain est au centre du texte comme dans une autobiographie (c'est le héros), mais il transfigure son existence et son identité, dans une histoire irréelle, indifférente à la vraisemblance" (Colonna 2004 : $75)^{7}$. Otro aspecto llamativo del libro de Colonna, por ser un tema dominado por el mundo francófono -que por otra parte, tal vez, no deba sorprendernos por la importancia que cobra la invención en su concepción de la autoficción-, es la recurrencia de la autoficción en la narrativa rioplatense: Copi (una mención, 2004: 195), pero sobre todo Borges y Gombrowicz son mencionados y comentados en diversas ocasiones de su libro (2004: 14), especialmente en el capítulo sobre la autoficción fantástica ${ }^{8}$.

Ahora bien, una parte significativa de la obra de César Aira se inscribe en este campo autoficcional. Esta obsesión del autor de ficcionalizar de alguna manera su propia vida recurriendo a juegos identitarios entre el protagonista o el narrador, por una parte, y el autor, por otra parte, puede observarse en textos tan diversos como Embalse (1992), El llanto (1992), Cómo me hice monja (1993), La costurera y el viento (1994), La serpiente (1997), El Congreso de literatura (1997), Las curas milagrosas del doctor Aira (1998), La trompeta de mimbre (1998) y El juego de los mundos (2000). En todas estas obras, se produce una homonimia

\footnotetext{
${ }^{5}$ La definición original de Colonna es la siguiente: "Tous les composés littéraires où un écrivain s'enrôle sous son nom propre (ou un dérivé indiscutable) dans une histoire qui présente les caractéristiques de la fiction, que ce soit par un contenu irréel, par une conformation conventionnelle (le roman, la comédie) ou par un contrat passé avec le lecteur" (2004: 70-71).

${ }^{6}$ Colonna propone la categorización siguiente, no como un modelo estable sino como un "détecteur d'approche" (2004: 146) que carece de cualquier dogmatismo: "I'autofiction fantastique" (2004: 75-92), "I'autofiction biographique" (2004: 93-117), "I'autofiction spéculative" (2004: 119134) ou "l'autofiction intrusive (autoriale)" (2004: 135-144)

${ }^{7}$ Alberca retoma la definición de la autoficción fantástica de Colonna y añade un matiz importante al apuntar que "el autor, en un movimiento de alejamiento máximo de su persona, llega incluso a burlarse de sí mismo y de su propio pasado y termina por confluir en una realidad imaginaria que sin embargo en alguna medida le compromete también" (2007: 190). A su vez, la subcategoría de la autoficción fantástica, junto a las de la "autoficción biográfica" -que también forma parte de la tipología de Colonna- y "autobioficción", constituyen el cuadro inacabado del campo autoficcional (Alberca 2007: 182).

${ }^{8}$ La siguiente afirmación de Premat parece corroborar la observación llamativa de Colonna: "Por razones variadas que se podría intentar desarrollar, la autofiguración de autor fue quizás más perceptible, inmediata y vigente en países periféricos, en donde escribir supuso no sólo 'inventar' una obra sino situarse en un proceso de 'invención' de una literatura nacional. El caso de la Argentina, como el de otros países en América Latina, es en este sentido significativo" (Premat 2005: 316). El estudio de José Amícola, Autobiografía como autofiguración (2007), también alude a esta referencia de Colonna.
} 
explícita (mediante el nombre efectivo del autor) ${ }^{9}$. En algunos casos, sin embargo, la identificación se opera a través de un nombre deformado (Cédar Pringle de $E$ l volante) o, aún más ambiguo, mediante un narrador anónimo (como en Un sueño realizado).

En esta última situación (una práctica frecuente también en la obra de Vila-Matas), la identidad entre autor, narrador y protagonista se ratifica de manera implícita por una serie de rasgos que el narrador comparte con el escritor biográfico. Hay toda una serie -in crescendo- de obras recientes que pertenecen a esa categoría: Taxol, precedido de Duchamp en México y La Broma (1997), Cómo me reí (2005), La cena (2006), El todo que surca la nada (2003), El cerebro musical (2005), La vida nueva (2007), etc.

Conviene distinguir en el amplio "espacio autoficcional"10 de la obra de Aira entre una vertiente más extravagante y a la vez rica en reflexiones metaficcionales, la del escritor fracasado-Sabio Loco (por ejemplo, El congreso de literatura, Las curas milagrosas del Doctor Aira) y una vertiente más autobiográfica en la que recuerda o recrea su infancia -el niño Aira- en Coronel Pringles (por ejemplo, El Tilo y Cómo me reí). En este sentido, Cómo me reí (2005) constituye un relato interesante desde un punto de vista genérico porque su hibridez matiza una oposición demasiado tajante entre las dos vertientes definidas del espacio autoficcional. Es decir, si bien parece pertenecer a una modalidad más biográfica, contiene suficientes elementos que permiten conectar el relato con la dimensión más irreal y fantástica de la autoficción airiana.

\section{De LA APARIENCIA REFERENCIAL A LA POSTURA AUTORIAL}

Queremos explicitar la figura de autor que se dibuja de manera fragmentaria (mediante los códigos autorreferenciales y algunas máximas airianas) en Cómo me ré a partir de la pregunta-crucial-por el efecto de las novelas del narrador que inicia este relato. La vuelta a la infancia y a la adolescencia que genera esta pesquisa de las raíces del problema receptor (el efecto) desemboca paradójicamente en lo que el narrador supuestamente más aborrece, la gratuidad y el humor. Por tanto, sus recuerdos pringlenses provocan nuevamente (son) risas, esta vez en los lectores extraliterarios, y reafirman la poética del nonsense de Aira (Decock 2014).

A medida que avanza el relato, también se intensifica la imagen patética de un ser atormentado, víctima de su propio programa vampirista (94-97). Esta constatación nos incita a realzar algunos paralelismos importantes con la concepción desacralizada de la identidad autorial en la obra narrativa de Vila-Matas, particularmente, según ésta se plasma en su novela El mal de Montano (2002). Se crea, en efecto, la sensación de que en las obras de Aira y Vila-Matas se da un

\footnotetext{
${ }^{9}$ Es de notar que el culto onomástico de Aira ya aparece desde su primera obra, Moreira (1975), y que sigue presente con un vigor particular en sus obras más recientes.

10 Para este término nos inspiramos en la noción equivalente de "espacio biográfico" de Leonor Arfuch (2002) cuyo estudio se centra en las nuevas formas autobiográficas (con un lugar central para la entrevista) y en la teorización contemporánea del sujeto.
} 
proceso conflictivo de "desidentidad", o sea, una identidad no resuelta del todo que se balancea entre el reflejo neo-narcisista y la disolución ${ }^{11}$. Sin embargo, visto el contexto del sinsentido y las contradicciones, ¿qué credibilidad, al fin y al cabo, se puede otorgar a esta figura de autor patética? Por ello, nos parece lícito postular el simulacro de la desidentidad en Cómo me reí tomando en cuenta los diferentes planos autoficcionales de su obra, que no pueden estudiarse de manera desarticulada entre sí y la sintonía -a pesar de las obvias diferencias-con la obra de Vila-Matas.

Con la pregunta metarreflexiva sobre el efecto en Cómo me ré, se tematiza nuevamente en la ficción un aspecto central de la literatura de Aira, a saber, su recepción polémica, hasta tal punto que creemos que esta autosuficiencia parece ser su principal condición de existencia. En cierto sentido, el lamento sobre el efecto que producen las obras del protagonista es el motivo de la escritura de esta novela, lo cual se trasluce también en las primeras líneas del texto: "Deploro a los lectores que vienen a decirme que 'se rieron' con mis libros, y me quejo amargamente de ellos [...]. Es un lamento constante en mí; puedo decir sin exagerar que esos comentarios han envenenado mi vida de escritor" (2005: 7).

Como suele ocurrir también en otras novelas, la cuestión del efecto literario se centra alrededor de la figura de autor plasmada en Cómo me reí. En este sentido, la imagen que se instala y se reafirma en cada texto condiciona también la interacción entre el texto y el lector. Ahora bien, si atendemos a los mecanismos de identificación que están en la base de este proceso circular, nos damos cuenta de que las figuras autorreferenciales son el código clave del conjunto. Entre otras, se evoca la imagen del "niño inteligente" ya presente en El Tilo - fui uno de esos niños inteligentes" (59), "superioridad intelectual" (81)-; también hallamos en varias ocasiones el tópico del genio $(33,93)$ o el del raro, del outsider: "Me hice fama de raro, de traga" (78), "... qué raro es este tipo" (19), "Entre ellos seguía siendo el 'sapo de otro pozo'" (51). Otro código que no suele faltar en esta constelación es el que alude a la idiotez: "Dejé a Susy con una vecina, me puse mi mejor traje (el de invierno), y fui a recibirlo [el Premio Konex] trémulo de expectativa, con mi habitual mueca idiota momentáneamente transfigurada en sonrisa idiota" (112). Y finalmente, también se observa la paradójica coexistencia de esa misma idiotez con la genialidad cuando el protagonista cae en la trampa de su amiga y su madre ${ }^{12}$, como se refleja en la cita siguiente: "Y serias, convincentes, verosímiles, al menos lo suficiente para hacer caer al ingenuo distraído que era yo. Supongo que no se necesitaba mucho. Qué increíble que yo pasara

\footnotetext{
11 Es interesante recurrir a la noción de "desidentidad" que Grossman desarrolla con respecto a la desfiguración en la conclusión de su estudio: "A la fois une et plus d'une. Ce qui signifie s'identifier non à une image mais au mouvement d'une image, en chacun des points où elle se stabilise provisoirement, dans ce défilé qui la fait plurielle, changeante. La désidentité dirait ce lien incessant de la forme aux mouvements qui la déforment. Alors l'identité est un théâtre. L'inverse même de la représentation narcissique de soi, cette mise en scène qui se joue sur la scène vide d'une psyché désertée" (Grossman 2004: 115). Esta idea de la superación del narcisismo modernista se encuentra también en la noción del ego "neo-narcisista" de Alberca (2007: 42).

12 Para unanálisis más completo del papel de idiota en la autofiguración airiana, véase el capítulo "Aira: el idiota de la familia" (237-251) en el estudio de Julio Premat (2009).
} 
por el genio de la banda, el superinteligente. Visto en retrospectiva, fríamente, nadie que no fuera un completo imbécil podía ser víctima de esa farsa" $(31)^{13}$.

Queda claro que todos estos códigos terminan por construir una determinada figura autorial, un ethos discursivo (Maingueneau 1993, Amossy 1999) en el texto literario. A su vez, este ethos discursivo se difunde entre los lectores, orientando sus próximas lecturas airianas y se amplifica por la crítica, articulando de esta manera también el campo literario (postura autorial). Efectivamente, en varias ocasiones, el texto da cuenta de un interés por los otros profesionales de la escritura, de cierta conciencia de la posición particular que ocupa el protagonista autoficcional en el campo de las letras, pero siempre con una ironía que traduce un anhelo de subvertir la imagen tradicional del escritor: "No puedo concebir que a un escritor de verdad, a cualquiera de mis ídolos o modelos, se le acercaran los lectores a decirles cuánto se habían reído con sus libros" (9). Y también: "Y aunque no lo hubiera dicho, basta pensarlo un momento, basta tener el más leve conocimiento del trabajo solitario y difícil de un escritor, para darse cuenta de que es una grosería. Solo estaría justificado con el autor de uno de esos libros que se llaman 'Nuevos Chistes de Gallegos'" (10).

Obviamente, en el segundo fragmento, el narrador-escritor defiende supuestamente los valores canónicos de la literatura que la obra prolífica de Aira no deja de poner en entredicho al oponerles una escritura de la frivolidad y la ligereza. A la luz de esta singular postura con la que Aira se manifiesta, cabe interpretarse también el gesto reivindicativo con respecto a su genealogía literaria. Aira tiene el mérito de haber rescatado, principalmente a través de sus ensayos y artículos, una "serie alternativa" de la tradición literaria argentina compuesta por narradores como Raúl Damonte Copi, Manuel Puig, Osvaldo Lamborghini y Roberto Arlt. Desde este punto de vista, es llamativo que, de manera aún más explícita que por ejemplo en El Tilo, la figura de Osvaldo Lamborghini ocupe un lugar destacado -"un gran escritor", "mi maestro" (35)- entre sus recuerdos pringlenses: "Desde que O. murió, hace veinte años, yo atesoro cada recuerdo que tengo de él, y los recuerdos que no le hacen honor (como éste, que sigo considerando uno de sus puntos flojos) los reinterpreto y les doy vueltas, y me las arreglo, con mi propio oficio de escritor aprendido entretanto (él fue mi maestro) para transformarlos de un modo u otro" (35) 14 . La marginalidad que simboliza Lamborghini en el campo literario argentino caracteriza también la figura de autor que se pone en escena en la narrativa de Aira, tanto en la dimensión biográfica como en la dimensión más fantástica de su obra autoficcional ${ }^{15}$.

\footnotetext{
${ }^{13}$ Cabe señalar un último código que completa la serie enumerada, a saber, el de ser un escritor prolífico (a pesar de afirmar lo contrario en la cita siguiente): "Con el paso del tiempo, mis nuevos 'amigos' se volvieron casi exclusivamente lectores, que leían mis libros (estos inundaban las librerías, no porque yo fuera naturalmente prolífico sino porque el sistema me obligaba a multiplicarme)..." (96).

${ }^{14}$ No cabe duda de que con la inicial "O." se refiere a su amigo Osvaldo Lamborghini (1940-1985). Sabiendo que Cómo me reí se publica en el año 2005, la indicación temporal "hace veinte años" en el fragmento citado aporta un argumento unívoco.

${ }^{15}$ Aira no ha dejado ocasión para asociar a Lamborghini con una imagen de autor no convencional, como atestiguan el final del prólogo a su edición de las obras póstumamente publicadas de
} 
Crucial -aunque no lo parezca a primera vista- nos parece, en este contexto, la observación siguiente que el narrador formula a propósito de Finita Feijóo, una chica excéntrica -también outsider como el protagonista y como Lamborghini- que formaba parte de aquel grupo de amigos de Pringles: "Y además, no era central (ni quería serlo, todo su sistema se oponía): era marginal. No podía ser de otro modo, con ese aspecto y ese carácter. Pero de algún modo lograba que esa marginalidad huidiza se volviera un centro" (57). Según nuestro razonamiento previo, se podría leer este fragmento en clave metafórica para la propia posición excéntrica y privilegiada que Aira ha llegado a ocupar paradójicamente dentro del campo literario argentino ( $\mathrm{y}$, por extensión, hispanoamericano) a la cual también ha contribuido la singular política de edición del autor -la famosa superproducción airiana- que consiste en abundar de manera alternativa el mercado editorial (Mondadori, Beatriz Viterbo, Mansalva, Eloísa Cartonera, etc.) y desafiar de esta manera las leyes y los valores del sistema literario ${ }^{16}$.

\section{Aira/Vila-Matas: esbozo de UnA FIgURA AUtORIAL PATÉtICA}

Además de los argumentos expuestos en la introducción, hay varios motivos que nos han inducido a proponer un breve acercamiento comparativo de las modalidades autoficcionales de César Aira y Enrique Vila-Matas: la problematización de la identidad narrativa, la construcción paradójica de una figura de autor, el común interés por los autores raros y excéntricos, el descentramiento hermenéutico, la recurrencia de la metarreflexividad, el gusto por la ironía y la paradoja, el desencuentro en la instancia de la recepción, etc. Más allá de las diferencias incontestables entre ambas obras, hay entonces una serie de afinidades conceptuales tematizadas extensamente en sus obras respectivas.

El objetivo de esta última parte es, mediante el enfoque comparativo, indagar en los elementos más característicos de los espacios autoficcionales de Vila-Matas y Aira. Proponemos centrarnos, en efecto, en la identidad narrativa y en la figura de autor expuesta en las respectivas obras narrativas al destacar sus convergencias y desemejanzas. Ya hemos visto que el protagonista de Cómo me reí se presenta como un ser atormentado, una víctima de su estilo vampirista ${ }^{17}$, de su frialdad intelectual:

\footnotetext{
Lamborghini, titulada Novelas y cuentos (1988) - - ... simplemente se mantuvo al margen de la cultura oficial, con lo que no perdió gran cosa"-y, también, la entrevista siguiente con Aira sobre Gombrowicz y Lamborghini: "Cualquier cosa: un encuentro con César Aira" (2006).

${ }^{16}$ En este sentido, la política de edición innovadora de Aira presenta similitudes con la noción de "paramercados" -desarrollada en la introducción del libro El valor de la cultura- que "replantean la lógica del mercado contribuyendo a su variabilidad" (Cárcamo-Huechante et al. 2007: 10-11).

17 Véase también El congreso de literatura (1997) como otra muestra del vampirismo estilístico (plasmado en una estética de la apropiación de estereotipos en el caso de Aira y de citas literarias falsas o auténticas en el caso de Vila-Matas) que condiciona la relación con el prójimo en las obras de estos dos autores. La cita siguiente de Cómo me reí resulta esclarecedora al respecto: "Pero al cabo de un tiempo me hastiaba y no lo soportaba más. ¿Qué había pasado? Que su novedad se había agotado, y el interés que me había producido se apagaba, y la repetición de su discurso y sus reacciones y opiniones me cansaba y deprimía" (94-95).
} 
Porque yo repetía la maniobra esperando, contra toda evidencia, que alguien alguna vez mostrara algún interés por mí. Eso nunca ocurrió, lo que me obligó a escribir, a mostrarme en libros ante una curiosidad difusa e invisible, un interés de nadie que yo debía crear. ¿Y cómo crearlo, a falta de verdadero talento, sino con atracciones más y más disparatadas, a medida que iba creciendo mi soledad? [...] No hago ironía cuando me culpo de lo que me pasa. (Aira 2005: 96)

A partir de este fragmento significativo ya podemos destacar toda una serie de rasgos constitutivos que se hallan también en la figura autorial patética expuesta en el ciclo vilamático de Bartleby y compañía (2000), El mal de Montano (2002) y París no se acaba nunca (2003). En El mal de Montano, que es la otra cara de la enfermedad de Bartleby y compañía, se nos presenta un protagonistaautor enfermo de literatura, del exceso quijotesco de sus lecturas y se tematiza la obsesión vilamática de la desaparición, concretamente una disolución del yo en las citas de otros autores, tema que desarrolla también en su novela Doctor Pasavento (2006).

Lo común entre los protagonistas autoficcionales de Cómo me reí y El mal de Montano -como casos paradigmáticos de un fenómeno recurrente en sus obras- es que se trata a menudo de yoes melancólicos, encerrados en una dolorosa dialéctica de revelación y ocultamiento. Son seres acomplejados que encarnan una figura autorial desacralizada y que parecen dominados por un afán de deshacerse de su identidad. Ahora bien, ¿cómo aproximarse a ese problemático sujeto enunciador, a ese yo múltiple, a esa (auto)conciencia narrativa paranoide y casi patológica? ¿Cuáles son los puntos en común en las estrategias narrativas y discursivas tras el proyecto de estos escritores? ¿Y cómo interpretar esa dialéctica de revelación y ocultamiento que siempre deja al lector en una zona hermenéutica insegura?

En El mal de Montano se observa también el fantasma del autor suizo Robert Walser -fruto de esa fascinación de Vila-Matas por las "rarezas" literarias-, con quien se identifica el protagonista Rosario Girondo. En efecto, esta novela transgenérica y caleidoscópica, que trata la vida de un hombre enfermo de literatura, está marcada por una narración que se va contradiciendo y transformando a lo largo de los cinco capítulos del libro, adscritos todos a una forma genérica diferente (el ensayo crítico, el manual de teoría literaria, la conferencia, el diario personal, el diccionario) y a lo largo de los cuales la ficción inicial se convierte en una realidad. Sin embargo, lo que está en juego en esta multiplicidad genérica de un texto "a caballo entre el ensayo, la ficción y lo autobiográfico" (2002: 189) se entiende tal vez mejor situándolo en el amplio espacio de la autoficción ${ }^{18}$.

Aunque no aparece el nombre del autor en El mal de Montano, sobran los elementos biográficos (los destinos recorridos, los autores citados, etc.) que pueden ratificar la identificación entre el narrador homodiegético Rosario Giron-

18 Pozuelo Yvancos (2010) propone la "figuración del yo" como noción alternativa a la de autoficción y destaca el distanciamientoirónico del yo figurado con respecto al autor y la voz reflexiva en un análisis agudo de El mal de Montano y las otras obras que componen este ciclo narrativo de Vila-Matas. 
do -que a su vez proyecta su obsesión literaria en su supuesto hijo Montano- y el autor Vila-Matas. Ya desde las primeras páginas de la novela se explora el tema del doble en su dimensión infinita y lúdica: "Quizá la literatura sea eso: inventar otra vida que bien pudiera ser la nuestra, inventar un doble" (2002: 16). A lo largo de la novela, las alteraciones y los desdoblamientos del yo narrativo -lúdicos y contradictorios- no solo problematizan la inscripción narrativa del yo en el texto (¿Quién narra?), sino que nos invitan también a una reflexión sobre la identidad personal (¿Cómo se concibe la cuestión de la identidad?).

Queda claro que se trata de una identidad fragmentada bajo el signo de la búsqueda. Si bien el narrador de El mal de Montano evoca en el fragmento siguiente la concepción moderna y posmoderna de la identidad del sujeto, es la segunda la que predomina en todo el relato:

\begin{abstract}
Antes de que el mundo fuera un país extranjero, la literatura era un viaje, una odisea. Había dos odiseas, una era la clásica, una epopeya conservadora que iba desde Homero a James Joyce y en la que el individuo regresaba a casa con una identidad reafirmada, a pesar de todas las dificultades [...]. La otra odisea era la del hombre sin atributos de Musil, que se movía, al contrario de Ulises, en una odisea sin retorno y en la que el individuo se lanzaba hacia delante, sin volver jamás a casa, avanzando y perdiéndose continuamente, cambiando su identidad en lugar de reafirmarla, disgregándola en aquello que Musil llamaba "un delirio de muchos". (Vila-Matas 2002: 275-276)
\end{abstract}

Precisamente esa disolución del sujeto en un "delirio de muchos" se produce en el espejo ${ }^{19}$ de autores mitificados en el que el narrador se mira y con los que se compara en su diccionario de diaristas (segunda parte). En algunos momentos, cuando Girondo llega a encarnar la Literatura para salvarla, esta disgregación del yo se desliza aún hacia la extinción, el anonimato y, al fin y al cabo, la muerte. Así observa Girondo en su diario: "Hoy eres Girondo y mañana Walser y tu nombre verdadero se pierde en el universo, quieres acabar con los mezquinos sueños de supervivencia de los escritores, quieres inscribirte con tus lectores en un mismo horizonte anónimo donde establecerías por fin con la muerte una relación de libertad" (297).

Ahora bien, en la encrucijada de las diversas cogitaciones metafísicas (sobre la identidad individual perturbada) y metaficcionales (sobre la esencia y la salvación de la literatura) del narrador (en realidad, el alter ego de Vila-Matas), llega a construirse una figura de autor. La continua contemplación del yo multiplicado en la otredad de sus colegas-escritores, termina por despertar la curiosidad del lector por la posibilidad de una representación del autor. Podemos ver también en los nombres más recurrentes (Walser, Kafka, Borges, Pessoa, etc.) de

\footnotetext{
${ }^{19}$ Cabe señalar también que esta práctica autoficcional se acerca a la definición de la "autoficción especular" según aparece en la tipología propuesta por Colonna: "Reposant sur un reflet de l'auteur ou du libre dans le livre, cette orientation de la fabulation de soi n'est pas sans rappeler la métaphore du miroir. Le réalisme du texte, sa vraisemblance, y deviennent un élément secondaire, et l'auteur ne se trouve plus forcément au centre du livre; ce peut n'être qu'une silhouette; l'important est qu'il vienne se placer dans un coin de son œuvre, qui réfléchit alors sa présence comme le ferait un miroir" (2004: 119).
} 
la impresionante biblioteca vilamática una estrategia muy fértil -de forma más explícita y universal que en el caso de Aira (más centrado en el campo argentino)- de imponer su propio canon.

A pesar de tematizar en El mal de Montano algunas de las principales preocupaciones respecto al descentramiento del sujeto posmoderno que corresponden a la diferente autoconciencia del yo en nuestra época y que implican ese "efecto de desaparición del autor en el texto", se trata en el caso del experimentalismo genérico de Vila-Matas más de un anhelo estético de apertura para la novela -son frecuentes las críticas al realismo y a la novela española $(65,99$, etc.)- que de una verdadera reflexión ontológica sobre la identidad del sujeto.

¿No debería verse tras todo esto, o sea, en la exposición de su experiencia literaria y de sus vericuetos existenciales, por un lado y en los juegos de ocultamiento (el pseudónimo, el anonimato, la mistificación, etc.) por el otro, una estrategia de autofiguración? ¿No sería más adecuado concebir, entonces, el supuesto problema identitario como una impostura de la desidentidad? Es cierto que esta especie de autorretrato ${ }^{20}$ disimulado que Vila-Matas ya va construyendo desde antes de Bartleby y compañía tiene una función hermenéutica importante. Esta figura de autor es, en realidad, el reflejo de un doble deseo encarnado por los dos sujetos constitutivos de la comunicación literaria (el autor y el lector). Recordemos que Roland Barthes, al matizar su gesto iconoclasta después de haber proclamado la muerte del autor (1969), ya había expresado que como lector deseaba a la figura de autor en Le plaisir du texte (1973). En efecto, el lector de El mal de Montano necesita recurrir a esa figura de autor para visualizar las coordenadas significativas que den sentido al texto. Va en busca de elementos de legibilidad en la infinita selva rizomática de referencias intertextuales y en la indecibilidad del sujeto. Su función operatoria es, como Foucault lo ha explicado en su concepto de la "fonction-auteur", la de limitar de alguna manera la proliferación de sentido (Couturier 1995: 8).

Sin embargo, aquí también el autor expresa recíprocamente ese deseo de figurar en el texto bajo la forma de un yo autorial proyectado en una serie de alter egos. Por esa misma razón, invita al lector a penetrar en el misterio de su obra mediante los dispositivos de la autoficcionalidad y metaficcionalidad, como se ha mostrado anteriormente. Creemos pues que la figura autorial en sus variantes autoficcionales (la renuncia a la escritura de Bartleby y compañía, el aprendizaje literario del escritor principiante en París no se acaba nunca, la obsesión por la literatura de Montano, etc.), es lo que proporciona cierta coherencia y, por tanto, da una forma de sentido al conjunto de su obra narrativa.

Volvamos ahora a la obra de César Aira a fin de detenernos también en algunas divergencias entre ambos proyectos de escritura mitográfica y de esbozar algunas conclusiones sucintas, más allá de las novelas individuales comparadas. Queda claro que ambos autores luchan con una búsqueda de la esencia de la

\footnotetext{
${ }^{20}$ Resulta particularmente interesante el uso de ese término que tiene su origen en la pintura -el autorretrato como imagen o reflejo del pintor en el espejo- donde fue practicado por artistas como Rembrandt entre otros porque permite establecer un nexo con la categoría de la autoficción especular de Colonna (2004).
} 
literatura - plasmada en sus obras en una pesquisa de la forma literaria- pero que las modalidades de tematizar esta exploración son diferentes. En el caso de Vila-Matas suele adoptar una forma más negativa a pesar del humor y la ironía, manifestándose en los tópicos del silencio, el fracaso, la desaparición, la ausencia e incluso la imposibilidad de la escritura. En cambio, en la obra de Aira, a pesar de la radicalidad del gesto vanguardista, esta crisis suele tomar una forma más afirmativa y el vacío se torna en un mundo de potencialidades y en el origen de una narración continua.

Estas modalidades bastante divergentes se traducen también en una semantización sui generis de la figura de autor (nos referimos a la imagen que domina en el conjunto de estas obras narrativas respectivas y que hay que matizar, por ende, para cada texto particular). La autofiguración paranoico-depresiva de Vila-Matas desemboca a menudo en un ser simbólico y ensimismado que está atravesando una grave crisis de escritura (el autor nunca aparece con su propio nombre y el suicidio es un tema recurrente en esta obra). De hecho, asistimos a la disolución de la identidad narrativa en la laberíntica textualidad vilamática, o sea en el entrecruzamiento de las múltiples lecturas y en la marea de citas literarias auténticas o apócrifas.

En cuanto a Aira, su figura de autor parece más inasible y se inscribe en una postura basada en la desautorización irónica del yo autor-narrador-protagonista, erradicando casi siempre la dimensión trágica presente en la textualidad de Vila-Matas. La imagen preponderante es la del autor/artista extravagante o del científico loco, que dosifica de manera imprevisible los ingredientes básicos de la genialidad y la idiotez. Se manifiesta a menudo en avatares farsantes que encarnan la imagen opuesta del arquetipo del escritor tradicional y se sitúa por tanto en un lugar periférico con respecto al campo cultural argentino. El gesto provocador de Aira, al transmutar los valores canónicos de la literatura (la ligereza versus la profundidad, la improvisación versus el esfuerzo, la chapucería versus la perfección, etc.), muestra hasta qué punto la postura de un autor es un proceso de índole acumulativa (Meizoz 2012: 46-47) que se construye en simultáneo con la dimensión autoficcional de una obra narrativa. En este sentido, es muy significativo que Vila-Matas también se haya posicionado hasta en sus últimos textos, en ensayos, entrevistas y conferencias, como un outsider, un autor raro en el campo literario español, dominado, según Vila-Matas, por un realismo decimonónico (Ródenas de Moya 2012: 319). Cabe señalar, sin embargo, que también es posible observar en la última etapa de la autofiguración vilamática, después de la etapa de un autor raro y de culto, un Vila-Matas más popular o masivo. De modo parecido que en el caso de Aira, esta nueva dimensión de su postura no se puede desvincular de un gesto editorial importante (su salida de Anagrama en el 2009 para incursionar en Seix Barral y DeBolsillo) ${ }^{21}$.

Para concluir, se trata en ambos casos de una poética caracterizada por la impostura y la contradicción. Se destaca una relación simbiótica entre ficción y

\footnotetext{
${ }^{21}$ Véase al respecto el interesante trabajo de Palma Castro, Ramírez Olivares y Ríos Baeza (2012: 443-463) en el libro Enrique Vila-Matas. Los espejos de la ficción.
} 
teoría en las obras respectivas que dependen, por tanto, de la legibilidad de una figura autorial como elemento de cohesión vital. La identidad o la desidentidad del yo autoficcional, volviendo a Grossman, es una mera puesta en escena, una estrategia creativa para seguir escribiendo y explorando nuevos caminos para la literatura contemporánea. Queda claro que la intervención estratégica de Aira y Vila-Matas en el campo literario, al forjar una figura de autor singular en los diferentes planos del espacio autoficcional, ha contribuido a diversificar y enriquecer el sistema literario contemporáneo.

\section{OBRAS CITADAS}

Aira, César (1997): El congreso de literatura [1999]. Buenos Aires, Tusquets.

- (1998a): Las curas milagrosas del Doctor Aira. Buenos Aires, Simurg.

— (1998b): "Prólogo". En: Osvaldo Lamborghini: Novelas y cuentos. Barcelona, Ediciones del Serbal, pp. 7-16.

- (2003): El Tilo. Rosario, Beatriz Viterbo.

- (2005): Cómo me ré. Rosario, Beatriz Viterbo.

Alberca, Manuel (2007): El pacto ambiguo: de la novela autobiográfica a la autoficción. Madrid, Biblioteca Nueva.

Amícola, José (2007): Autobiografía como autofiguración. Estrategias discursivas del Yo y cuestiones de género. Rosario, Beatriz Viterbo.

Amossy, Ruth (dir.) (1999): Images de soi dans le discours. La construction de l'ethos. Lausana/ París, Delachaux et Niestlé.

Arfuch, Leonor (2002): El espacio biográfico. Dilemas de la subjetividad contemporánea. Buenos Aires, Fondo de Cultura Económica.

Barthes, Roland (1984): Le Bruissement de la langue. París, Seuil.

Cárcamo-Huechante, Luis E.; Fernández Bravo, Álvaro; y Laera, Alejandra (eds.) (2007): El valor de la cultura. Arte, literatura y mercado en América Latina. Rosario, Beatriz Viterbo.

Casas, Ana (ed.) (2012): La autoficción. Reflexiones teóricas. Madrid, Arco Libros.

Colonna, Vincent (2004): Autofiction et autres mythomanies littéraires. Auch, Editions Tristram.

Couturier, Maurice (1995): La figure de l'auteur. París, Seuil.

Decock, Pablo (2014): Las figuras paradójicas de César Aira. Un estudio semiótico y axiológico de la estereotipia y la autofiguración. Oxford/Berna: Peter Lang.

Epplin, Craig, y Penix-Tadsen, Phillip (2006): "Cualquier cosa: un encuentro con César Aira", CiberLetras, n. 15. Disponible en <www.lehman.cuny.edu/ciberletras/v15/epplin. html>. Última visita: 25.11.2014.

Foucault, Michel (1994): "Qu'est-ce qu'un auteur". En: Daniel Defert y François Ewald (eds.): Dits et Écrits. París, Gallimard, vol. I, pp. 789-821.

Grossman, Evelyne (2004): La défiguration. Artaud - Beckett - Michaux. París, Les Éditions de Minuit.

Jeannelle, Jean-Louis, y Viollet, Catherine (eds.) (2007): Genèse et autofiction. Louvain-laNeuve, Academia-Bruylant. 
Maingueneau, Dominique (1993): Le contexte de l'œuvre littéraire. Enonciation, écrivain, société. París, Dunod.

- (2004): Le discours littéraire: paratopie et scène d'énonciation. París, Armand Colin.

Meizoz, Jérôme (2007): Postures littéraires. Mises en scène modernes de l'auteur. Ginebra, Slatkine.

- (2012): "Posture d'auteur et dynamique autofictionnelle dans Mort à crédit". En: Joël Zufferey (ed.): L'autofiction: variations génériques et discursives. Louvain-la-Neuve, Harmattan/Academia, pp. 33-50.

Pozuelo Yvancos, José María (2010): Figuraciones del yo en la narrativa. Javier Marías y E. Vila-Matas. Valladolid, Cátedra Miguel Delibes.

Premat, Julio (ed.) (2005): Figures d'auteur / Figuras de autor. Cahiers de LI.RI.CO., n. 1.

Premat, Julio (2009): Héroes sin atributos: figuras de autor en la literatura argentina. Buenos Aires, Fondo de Cultura Económica.

Ríos Baeza, Felipe A. (ed.) (2012): Enrique Vila-Matas. Los espejos de la ficción. México D. F., Ediciones Eón.

Ródenas de Moya, Domingo (2012): "La novela póstuma o el mal de Vila-Matas". En: Ana Casas (ed.): La autoficción. Reflexiones teóricas. Madrid, Arco Libros, pp. 305-326.

Vila-Matas, Enrique (2000): Bartleby y compañía. Barcelona, Anagrama.

- (2002): El mal de Montano. Barcelona, Anagrama.

- (2003): París no se acaba nunca. Barcelona, Anagrama.

- (2005): Doctor Pasavento. Barcelona, Anagrama.

(2012): Aire de Dylan. Barcelona, Seix Barral. 